
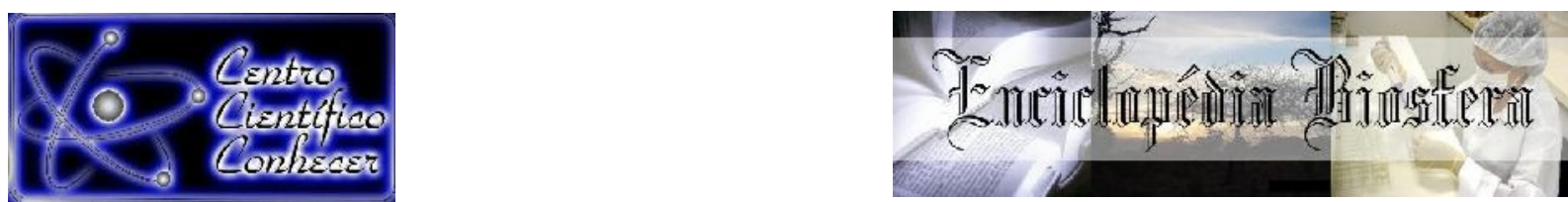

\title{
COMPOSIÇÃO FLORÍSTICA EM ÁREAS DE PASTAGENS NO PROJETO DE ASSENTAMENTO ASSURINI, EM ALTAMIRA, PARÁ
}

Cláudia Barbosa Cordeiro'; Maysa Lorrane Medeiros de Araújo2; Paulo Matheus Marques da Silva ${ }^{3}$, Laio Rodrigo Marques da Silva ${ }^{4}$; Maristela Marques da Silva

1'Discente do curso de Engenharia Agronômica da Universidade Federal do Pará, Campus de Altamira, Brasil. E-mail: clauagro97@gmail.com

2Discente do curso de Engenharia Agronômica da Universidade Federal do Pará, Campus de Altamira, Brasil.

${ }^{3}$ Discente do curso de Engenharia Agronômica da Universidade Federal do Pará, Campus de Altamira, Brasil.

${ }^{4}$ Docente, pesquisadora do curso de Engenharia Agronômica no Laboratório de Botânica e Ecologia da Universidade Federal do Pará, campus de Altamira, Brasil.

Recebido em: 15/11/2020 - Aprovado em: 15/12/2020 - Publicado em: 30/12/2020 DOI: 10.18677/EnciBio_2020D9

\begin{abstract}
RESUMO
Nas últimas décadas, a pecuária baseada em pastagens tem sido uma das principais atividades econômicas da Amazônia. No entanto, a supressão vegetal para formação das pastagens, a falta de manejo ou o manejo inadequado contribuem para redução das árvores e desenvolvimento de plantas espontâneas, podendo causar prejuízos e degradação. Objetivou-se com este trabalho realizar um levantamento das espécies de árvores e plantas espontâneas ocorrentes em áreas de pastagens de Urochloa brizantha Stapf em propriedades localizadas no município de Altamira, PA. O trabalho foi desenvolvido em três propriedades localizadas no Projeto de Assentamento Assurini em maio de 2016, em cada propriedade foram instaladas duas parcelas com dimensões de $25 \times 20$ metros $\left(500 \mathrm{~m}^{2}\right)$, cada. As plantas presentes nas parcelas foram organizadas nas categorias de ervas, arbustos, árvores, lianas e palmeiras. A identificação foi baseada no ANGIOSPERM PHYLOGENY GROUP IV (2016) e consulta a bibliografia especializada. Foram identificadas 49 espécies, distribuídas em 40 gêneros e pertencentes a 19 famílias botânicas. As 5 famílias botânicas de maior número de indivíduos foram Fabaceae, Asteraceae, Lecythidaceae, Lamiaceae e Salicaceae. As espécies de maior ocorrência foram a Geniparana (Gustavia augusta L.), Malícia (Mimosa pudica L.), Hortelã bravo (Hyptis atrorubens Point), Pata de vaca (Bauhinia forticata Link), Goiaba (Psidium guayava L.), Malva roxa (Urena lobata L.), Fedegoso (Senna hirsuta (Benth.) H.S. Irwin \& Barneby), Maria fecha porta (Mimosa policarpa Kunth), Joá bravo (Solanum viarum Dunal) e Malva branca (Waltheria indica L.). Quanto ao hábito de crescimento $45,32 \%$ são árvores, $27,68 \%$ são ervas, $24,22 \%$ são arbustos, $2,07 \%$ palmeiras arborescentes e 0,69\% lianas. As árvores foram representativas na área de estudo e destaca-se a importância de conservá-las nas pastagens, pois além de fornecer sombra ao gado bovino, controlam a erosão, melhoram a fertilidade do solo e retenção de água, contribuindo significativamente para evitar a degradação das pastagens.
\end{abstract}

PALAVRAS-CHAVE: árvores; espécies botânicas; pecuária.

ENCICLOPÉDIA BIOSFERA, Centro Científico Conhecer - Jandaia-GO, v.17 n.34; p. 114 


\title{
FLORISTIC COMPOSITION IN PASTURES AREAS IN THE ASSURINI SETTLEMENT PROJECT, IN ALTAMIRA, PARÁ
}

\begin{abstract}
In recent decades, pasture-based livestock has been one of the main economic activities in the Amazon. However, vegetation suppression to form pastures, lack of management or inadequate management contribute to the reduction of trees and the development of spontaneous plants, which can cause damage and degradation. The objective of this work was to survey the species of spontaneous trees and plants occurring in pasture areas of Urochloa brizantha Stapf in properties located in the municipality of Altamira, PA. The work was developed in three properties located in the Assurini Settlement Project in May 2016, in each property two plots were installed with dimensions of $25 \times 20$ meters $\left(500 \mathrm{~m}^{2}\right)$, each. The plants present in the plots were organized in the categories of herbs, shrubs, trees, lianas and palm trees. The identification was based on the ANGIOSPERM PHYLOGENY GROUP IV (2016) and consults the specialized bibliography. Forty-nine species were identified, distributed in 40 genera and belonging to 19 botanical families. The 5 botanical families with the highest number of individuals were Fabaceae, Asteraceae, Lecythidaceae, Lamiaceae and Salicaceae. The most common species were Geniparana (Gustavia augusta L.), Malice (Mimosa pudica L.), Mint bravo (Hyptis atrorubens Point), Pata de vaca (Bauhinia forticata Link), Goiaba (Psidium guayava L.), Malva roxa (Urena lobata L.), Fedegoso (Senna hirsuta (Benth.) H.S. Irwin \& Barneby), Maria closes the door (Mimosa policarpa Kunth), Joá bravo (Solanum viarum Dunal) and White Maul (Waltheria indica L.). As for the growth habit $45.32 \%$ are trees, $27.68 \%$ are herbs, $24.22 \%$ are shrubs, $2.07 \%$ arborescent palm trees and $0.69 \%$ lianas. The trees were representative in the study area and the importance of conserving them in pastures stands out, because in addition to providing shade to cattle, they control erosion, improve soil fertility and water retention, contributing significantly to avoid pasture degradation.
\end{abstract}

KEYWORDS: trees; botanical species; livestock.

\section{INTRODUÇÃO}

Atualmente o Brasil aparece em segundo lugar no ranking mundial dos maiores produtores e maiores exportadores de carne bovina, sendo abatidas 7,72 milhões de cabeças de bovinos e exportada 346.155 toneladas de carne in natura (IBGE, 2018). Aproximadamente $95 \%$ da carne bovina é produzida em regime de pastagens, onde a área total é de cerca de 167 milhões de hectares, sendo a maneira mais econômica e prática de produzir e disponibilizar alimentos para o gado bovino. Desse modo, as pastagens desempenham papel fundamental na pecuária brasileira, contribuindo para os baixos custos de produção (DIAS-FILHO, 2014; EMBRAPA, 2018).

Nesse cenário, as pastagens assumem papel de extrema importância para o êxito da pecuária em âmbito nacional, sendo necessárias condições adequadas de produção. Todavia, o que se percebe na prática é o predomínio de pastagens degradadas, sendo esse considerado um dos principais entraves no sistema de produção de gado bovino. Diversos fatores podem causar a degradação, entre eles a falta de adaptação ao meio da espécie cultivada, a má formação inicial, a perda da 
fertilidade do solo por falta de adubação de manutenção e o manejo inadequado, incluindo o superpastejo (TUFFI SANTOS et al., 2004).

A degradação das pastagens é um dos principais problemas para a manutenção da atividade pecuária em regiões tropicais e subtropicais, contribuindo para prejuízos econômicos e ambientais exacerbados. Cerca de 60 milhões de hectares na Amazônia Brasileira e no Brasil Central estão degradadas ou em processo de degradação (DIASFILHO, 2011). Assim, para Mota (2010), a maioria das pastagens no Brasil se caracteriza pela degradação, baixo potencial produtivo e, portanto, baixa capacidade de suporte animal, baixa produção e produtividade no produto final.

A princípio a degradação pode ser definida como uma simples alteração na botânica da pastagem, devido ao aumento da população de plantas espontâneas e consequente diminuição da população de capim. Esse aumento exacerbado de plantas espontâneas na pastagem é resultado do processo de degradação e não a causa desse processo (DIAS-FILHO, 2011).

No entanto, a medida que a densidade aumenta em determinada área intensifica-se a competição inter e intra-específica, sendo necessários a adoção de critérios de controle que visem diminuir os danos causados pela competição entre as plantas espontâneas e a espécie forrageira por água, nutrientes e luz esse processo pode ser acentuado, causando prejuízos ainda maiores decorrentes dessa disputa (SANTOS et al., 2004; RODRIGUES et al., 2010).

Desse modo, torna-se necessária a identificação correta das plantas espontâneas afim de diagnosticar e recomendar o método de controle mais eficiente. $O$ levantamento da composição florística usado para identificar as espécies presentes na pastagem, constitui uma importante ferramenta no embasamento técnico para recomendações de manejo e tratos culturais, seja para a implantação, recuperação ou condução das pastagens (MENEZES et al., 2010).

Assim, objetivou-se com este trabalho fazer um levantamento das espécies de árvores e plantas espontâneas ocorrentes em áreas de pastagens de Urochloa brizantha Stapf com idade por volta de 10 anos, em três propriedades localizadas no Projeto de Assentamento Assurini, no município de Altamira-PA.

\section{MATERIAL E MÉTODOS \\ Localização e caracterização da área de estudo}

O município de Altamira pertence a mesorregião sudoeste do Pará e a microrregião Altamira. A sede municipal está situada a latitude $3^{\circ} 12^{\prime} 37^{\prime \prime}$ Sul e longitude $52^{\circ} 13^{\prime} 03^{\prime \prime}$ Oeste, e altitude de 100 metros. Quanto aos aspectos climáticos, de acordo com a classificação de Köppen é do tipo equatorial Am (Dubreuili et al., 2019), apresentando duas estações climáticas bem definidas: o período de estiagem de julho a dezembro correspondente ao "verão" e o período chuvoso de janeiro a junho que corresponde ao "inverno", com precipitação pluviométrica anual girando em torno de $2.123 \mathrm{~mm}$ (SILVA et al., 2009). O trabalho foi desenvolvido no Projeto de Assentamento Assurini, em três propriedades rurais, em áreas de pastagens com Urochloa brizantha Stapf, no mês de maio de 2016. 
.FIGURA 1 Localização da área de estudo do P.A. Assurini, no município de Altamira-PA.

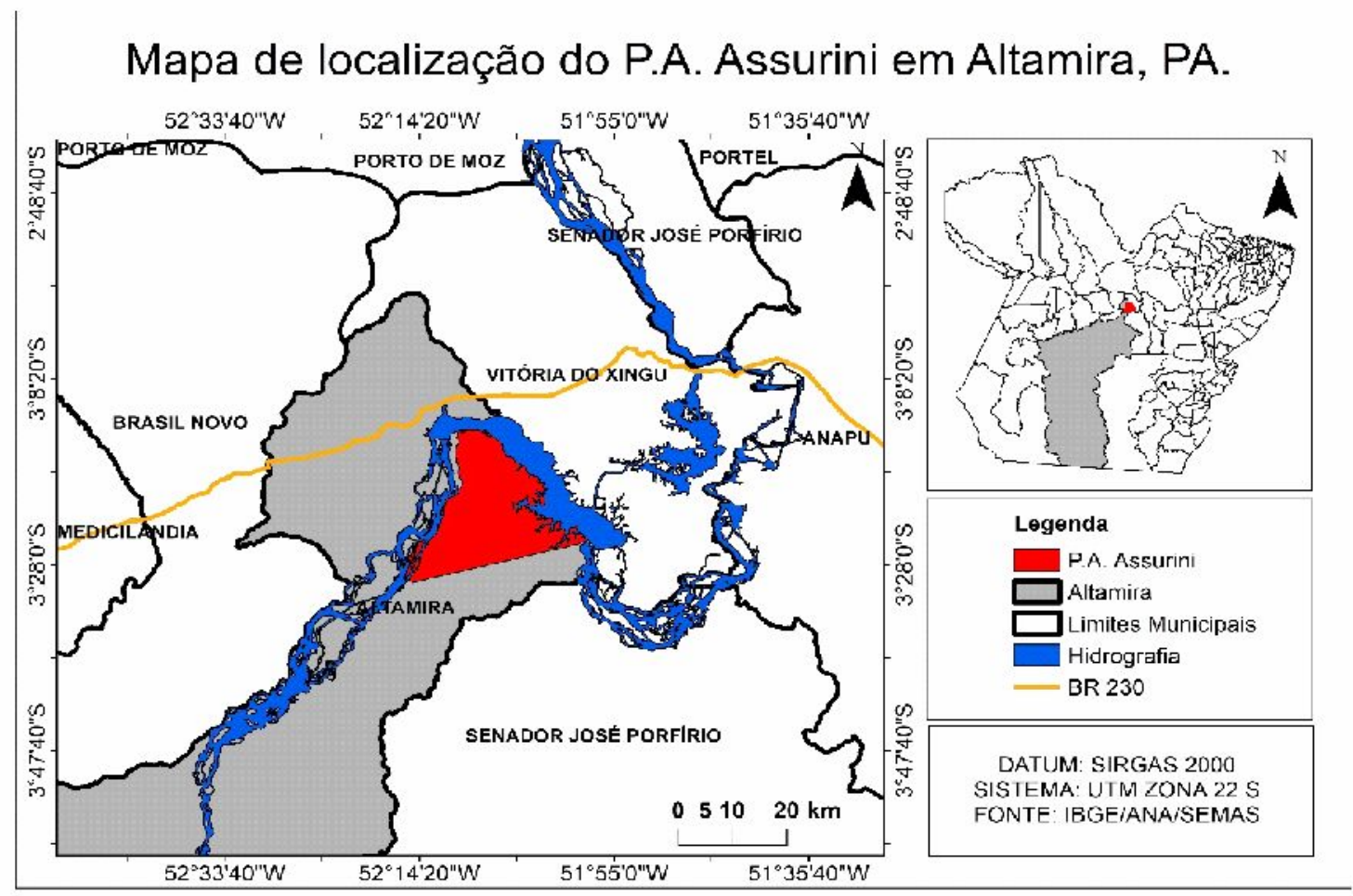

O Projeto de Assentamento Assurini foi criado no ano de 1995 e está localizado ao Norte do município de Altamira, às margens do rio Xingu com as seguintes coordenadas geográficas: $3^{\circ} 15^{\prime} 09.65^{\prime \prime S}$ e 5208'48.49"O; (Figura 1). O PA possui uma área de aproximadamente 47.232 ha e segundo o INCRA possui capacidade para 500 famílias.

Em se tratando de solos, predominam manchas de Argissolos Amarelos constituídos por material mineral, que têm como características diferenciais a presença de horizonte $B$ textural de argila de atividade baixa, Argissolos Vermelho-Amarelo são solos com muito baixa a média fertilidade natural, apresentando como principal restrição aqueles que ocorrem em ambientes com relevos movimentados, Neossolos Litólicos são solos pouco evoluídos e sem qualquer tipo de horizonte B diagnóstico e Gleissolos Háplicos são solos que encontram-se permanente ou periodicamente saturados por água, salvo se artificialmente drenados (CASTRO, 2017). No que se refere a atividade econômica, predomina no projeto de assentamento a agropecuária familiar de baixo e médio nível tecnológico, e destaca-se a pecuária de corte, há também a predominância de extensas áreas com cultivo de cacau (Theobroma cacao L.) e, em menor proporção, atividades como horticultura, silvicultura e piscicultura.

\section{Procedimentos metodológicos}

Para o levantamento da composição florística das pastagens foram estudadas três propriedades, em cada propriedade foi selecionada uma área de um hectare onde 
foi instalada duas parcelas com dimensões de $25 \times 20$ metros $\left(500 \mathrm{~m}^{2}\right)$ cada, totalizando $1.000 \mathrm{~m}^{2}$ por propriedade estudada. $\mathrm{O}$ estudo foi realizado no final do período chuvoso no mês de maio.

Em cada área foram inventariadas todas as plantas presentes nas parcelas, sendo coletados ramos férteis e estéreis das plantas não identificadas na área de estudo, para identificação no Laboratório de Botânica da Faculdade de Engenharia Agronômica, onde foram herborizadas e identificadas. A identificação foi baseada no ANGIOSPERM PHYLOGENY GROUP IV (2016), e consulta ao Manual de Identificação e Controle de Plantas Daninhas (LORENZI et al., 2014).

A sistematização dos dados foi baseada no número de plantas por família botânica e organizadas conforme o hábito de crescimento, nas categorias de ervas, arbustos, árvores, lianas e palmeiras, conforme Agarez et al., (1994). Os dados coletados foram organizados e analisados por meio de métodos da estatística descritiva, com sínteses apresentadas na forma de gráficos e tabelas pelo Word e Excel.

\section{RESULTADOS E DISCUSSÃO}

Foram identificadas 49 espécies, distribuídas em 40 gêneros e pertencentes a 19 famílias botânicas. As famílias botânicas mais representativas do levantamento, no que se refere a números de indivíduos foram Fabaceae (78), Lecythidaceae (32), Asteraceae (23), Solanaceae (21) e Malvaceae (20). As menos representativas foram Melastomataceae (5), Apocynaceae (4), Simaroubaceae (4), Urticaceae (1) e Connaraceae (1).

Lima et al. (2017), verificaram em um levantamento realizado em áreas de pastagens na região nordeste paraense 35 espécies de plantas espontâneas, distribuídas em 18 famílias, sendo cinco da família Fabaceae, cinco da familia Poaceae, três da família Asteraceae, três da família Cyperaceae e três da família Malvaceae. Ferreira et al. (2014), verificaram em pastagens degradadas na região Médio Vale do Rio Doce, Minas Gerais, 23 espécies de plantas espontâneas, distribuídas em dez famílias, sendo oito da família Poaceae, cinco da família Malvaceae e três da família Fabaceae.

As espécies de maior ocorrência, em número de indivíduos, encontradas na área de estudo amostrada foram a Geniparana (Gustavia augusta L.), Malícia (Mimosa pudica L.), Hortelã bravo (Hyptis atrorubens Point), Pata de vaca (Bauhinia forticata Link), Fumo bravo (Solanum velutinum Dunal), Goiaba (Psidium guayava L.), Malva roxa (Urena lobata L.), Fedegoso (Senna hirsuta (Benth.) H.S. Irwin \& Barneby), Maria fecha porta (Mimosa policarpa Kunth), Joá bravo (Solanum viarum Dunal) e Malva branca (Waltheria indica L.) (Tabela 1).

TABELA 1. Espécies botânicas de maior ocorrência na área de estudo do P.A. Assurini, em Altamira, Pará.

\begin{tabular}{llll}
\hline Nome da espécie/família & Hábito & Nome comum & $\begin{array}{l}\mathbf{N}^{\circ} \text { de } \\
\text { indivíduos }\end{array}$ \\
\hline Apocynaceae & & & \\
\hline Tabernaemontana angulata Mart. ex Müll.Arg. & Arbusto & $\begin{array}{l}\text { Jasmim de } \\
\text { cachorro }\end{array}$ & 3
\end{tabular}


Tabernaemontana flavicans Willd. ex Roem. \&

Schult.

Árvore

1

\begin{tabular}{|c|c|c|c|}
\hline \multicolumn{4}{|l|}{ Arecaceae } \\
\hline Attalea maripa (Aubl.) Mart. & $\begin{array}{l}\text { Palmeira } \\
\text { arborescente }\end{array}$ & Inajá & 6 \\
\hline \multicolumn{4}{|l|}{ Asteraceae } \\
\hline Chromolaena odorata (L.) R.M.King \& H.Rob. & Arbusto & Arnica do mato & 4 \\
\hline Erechtites hieracifolius (L.) Raf. ex DC. & Erva & Serralia brava & 8 \\
\hline Melampodioum perfoliatum (Cav.) & Erva & Estrelinha & 1 \\
\hline $\begin{array}{l}\text { Porophyllum ruderale (Jacq.) Cass. subsp. } \\
\text { ruderale }\end{array}$ & Erva & Couve cravinho & 8 \\
\hline Pulchea sagittalis (Lam.) Cabrera & Erva & Erva lucera & 2 \\
\hline \multicolumn{4}{|l|}{ Bignoniaceae } \\
\hline Fridericia cinnamomea (DC.) L.G.Lohmann & Liana & & 2 \\
\hline Handroanthus serratifolius (Vahl) S. O. Grose & Árvore & $\begin{array}{l}\text { Ipê amarelo } \\
\text { Ipê branco do }\end{array}$ & 4 \\
\hline Tabebuia insignis (Miq.) Sandwith & Árvore & brejo & 1 \\
\hline Tabebuia sp. & Árvore & Ipê roxo & 3 \\
\hline \multicolumn{4}{|l|}{ Connaraceae } \\
\hline Connarus erianthus Benth. ex Baker & Árvore & & 1 \\
\hline \multicolumn{4}{|l|}{ Fabaceae } \\
\hline Bauhinia acreana Harms & Árvore & Pata de vaca & 5 \\
\hline Bauhinia forficata LinK & Árvore & Pata de vaca & 12 \\
\hline Calopogonium mucunoides Desv. & Erva & Calopogonio & 4 \\
\hline $\begin{array}{l}\text { Cassia fastuosa Willd. ex Benth. } \\
\text { Chamaecrista xinquensis (Ducke) H.S.Irwin \& }\end{array}$ & Árvore & Canafístula & 7 \\
\hline Barneby & Árvore & Sucupirinha & 4 \\
\hline Desmodium adscendens (Sw.) DC. & Arbusto & Amor agarrado & 1 \\
\hline Inga capitata Desv. & Árvore & Ingá de metro & 2 \\
\hline Mimosa policarpa Kunth & Erva & & 9 \\
\hline Mimosa pudica L. & Erva & Malícia & 17 \\
\hline Senna hirsuta (Benth.) H.S. Irwin \& Barneby & Arbusto & Fedegoso & 10 \\
\hline Tachigali sp. & Árvore & & 5 \\
\hline Zornia reticulata $\mathrm{Sm}$ & Erva & & 2 \\
\hline \multicolumn{4}{|l|}{ Hypericaceae } \\
\hline Vismia cayennensis (Jacq.) Pers. & Árvore & Lacre branco & 5 \\
\hline Vismia japurensis H.G.Reich. & Árvore & Lacre vermelho & 7 \\
\hline \multicolumn{4}{|l|}{ Lamiaceae } \\
\hline Hyptis atrorubens Poit. & Erva & Hortelã bravo & 15 \\
\hline Hyptis suaveolens (L.) Poit. & Erva & Bamburral & 4 \\
\hline \multicolumn{4}{|l|}{ Lecythidaceae } \\
\hline Gustavia augusta L. & Árvore & Geniparana & 30 \\
\hline Lecythis lurida (Miers) S.A.Mori & Árvore & Jarana branca & 2 \\
\hline \multicolumn{4}{|l|}{ Malvaceae } \\
\hline Urena lobata L. & Arbusto & Malva roxa & 11 \\
\hline Waltheria indica $\mathrm{L}$. & Arbusto & Malva branca & 9 \\
\hline
\end{tabular}

ENCICLOPÉDIA BIOSFERA, Centro Científico Conhecer - Jandaia-GO, v.17 n.34; p. 119 


\begin{tabular}{|c|c|c|c|}
\hline Clidemia rubra (Aubl.) Mart. & Arbusto & & 5 \\
\hline \multicolumn{4}{|l|}{ Myrtaceae } \\
\hline Psidium guayava L. & Árvore & Goiaba & 11 \\
\hline Eugenia sp. & Árvore & Goiabinha & 3 \\
\hline \multicolumn{4}{|l|}{ Piperaceae } \\
\hline Piper peltatum L. & Arbusto & Pariparoba & 6 \\
\hline \multicolumn{4}{|l|}{ Salicaceae } \\
\hline Banara guianensis Aubl. & Árvore & Cabelo de cotia & 8 \\
\hline Casearia arborea (Rich.) Urb. & Árvore & Pau de pico & 5 \\
\hline Casearia pitumba Sleumer & Árvore & Tucandeira & 4 \\
\hline \multicolumn{4}{|l|}{ Sapindaceae } \\
\hline Pseudima frutescens (Aubl.) Radlk. & Árvore & $\begin{array}{l}\text { Pitomba-falsa } \\
\text { Pitomba de }\end{array}$ & 4 \\
\hline Talisia longifolia (Benth.) Radlk. & Árvore & macaco & 2 \\
\hline \multicolumn{4}{|l|}{ Simaroubaceae } \\
\hline Simarouba amara Aubl. & Árvore & Pau amargo & 4 \\
\hline \multicolumn{4}{|l|}{ Solanaceae } \\
\hline Solanum velutinum Dunal & Arbusto & Fumo bravo & 12 \\
\hline Solanum viarum Dunal & Arbusto & Joá bravo & 9 \\
\hline \multicolumn{4}{|l|}{ Verbenaceae } \\
\hline Stachytarpheta caynnensis (Rich.) & Erva & Gervão-azul & 4 \\
\hline Lantana camara L. & Erva & Camará & 6 \\
\hline \multicolumn{4}{|l|}{ Urticaceae } \\
\hline Cecropia concolor Wild & Árvore & Embaúba & 1 \\
\hline Total & & & 289 \\
\hline
\end{tabular}

Para Pelissari et al. (2011) grande parte das áreas de pastagens do Brasil são deixadas a segundo plano, muitas vezes por poucos investimentos voltados a pesquisas do controle de plantas espontâneas. Segundo Inoue et al. (2013), é importante, que haja, mais estudos para o controle de plantas espontâneas, com o propósito de indicar as ações para controle das espécies. Quanto ao hábito de crescimento dos indivíduos presentes nas áreas do levantamento, 45,32\% são árvores, $27,68 \%$ são ervas, 24,22\% são arbustos, 2,07\% palmeiras arborescentes e 0,69\% lianas.

FIGURA 2. Porcentagem das espécies por hábito de crescimento presente na área de estudo do P.A. Assurini, no município de Altamira, PA.

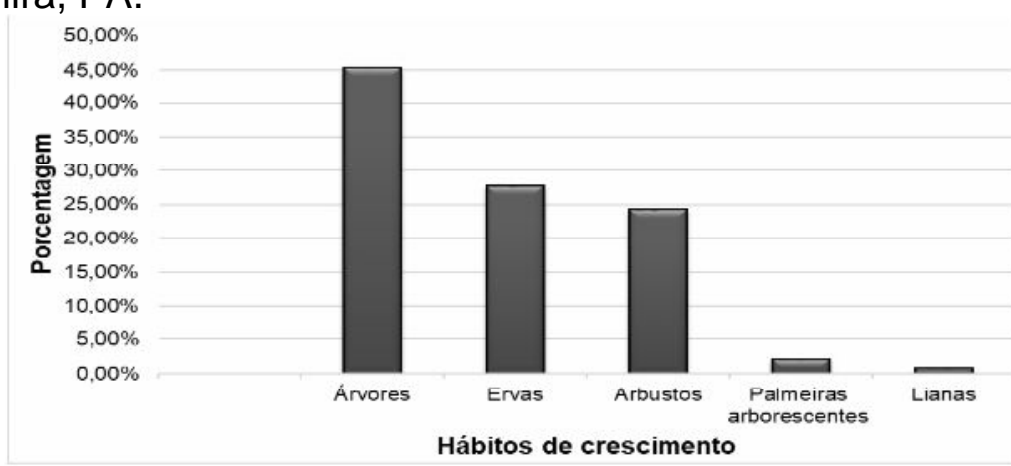


As espécies com hábito de crescimento tipo árvore foram representativas na área de estudo com destaque para a geniparana (Gustavia augusta L.) (30), pois é uma espécie de uso múltiplo que pode ser empregada na construção civil e também possui uso medicinal, onde sua raiz é utilizada como laxante e as folhas contra icterícia (LORENZI et al., 2015).

Outras espécies identificadas no presente estudo que possuem maior importância são Cassia fastuosa (canafístula), Inga sp. (ingá de metro), Bauhinia forficata LinK (pata de vaca), Attalea maripa (Aubl.) Mart. (inajá), Handroanthus serratifolius (Vahl) S. O. Grose (ipê amarelo), Tabebuia sp. (ipê roxo), Lecythis lurida (Miers) S.A.Mori (jarana branca), que são espécies de valor econômico e ecológico que podem ser utilizadas em programas de regeneração em áreas de preservação permanente, como também possuem uso medicinal.

As pastagens que possuem diversidade arbóreas de espécies nativas apresentam vantagens em relação a pecuária convencional, pois permitem a diversificação de produtos, aumento da produtividade animal, além de proporcionarem serviços ambientais (BHAGWAT et al., 2008). Além do mais, as espécies arbóreas nativas podem ser mais resistentes a condições desfavoráveis próprias do ecossistema, como sazonalidade e solos de baixa fertilidade, o que contribui para uma maior sustentabilidade dos sistemas, tornando-os mais resilientes e economicamente viáveis, sobretudo às comunidades de baixo poder aquisitivo (CASTRO;PACIULLO, 2006).

Por outro lado, grande parte das espécies encontradas na área de estudo, sobretudo as que possuem hábitos de crescimento erva e arbusto, podem ser consideradas indicadoras de que a pastagem em questão encontra-se degradada ou em processo de degradação. A degradação pode ser causada por uma série de fatores, entre eles a dificuldade de adaptação da espécie cultivada ao meio em que está inserida, a má formação inicial, a perda da fertilidade do solo pela falta de adubação de manutenção e o manejo inadequado, incluindo o superpastejo (TUFFI SANTOS et al., 2004). Assim as plantas espontâneas surgem como uma consequência da degradação.

Segundo Santos et al. (2004), quanto mais a população de plantas espontâneas cresce, maior é a competição, assim as plantas que possuem maior desenvolvimento acabam dominando a área, como consequência, as menores são inibidas e morrem. A competição das plantas espontâneas com a pastagem, refere-se ao processo que reduz ou remove fatores de crescimento indispensáveis para as forrageiras, como por exemplo, a luz, a água e nutrientes (SOUZA et al., 2003), além dessa competição, as plantas espontâneas podem comprometer o desenvolvimento da forrageira através da produção de substâncias químicas com efeito alelopático, reduzindo a germinação das sementes, o desenvolvimento, a produtividade e a qualidade da forrageira. A ocorrência de plantas espontâneas se torna ainda mais desfavorável quando dentre as espécies encontradas no local, algumas apresentam componentes tóxicos afetando os animais e podendo levar a morte.

As espécies tóxicas encontradas na área de estudo foram joá-bravo (Solanum viarum Dunal), que além de intoxicar pode ferir os animais, pois possui espinhos e, também foi identificada a presença de camará (Lantana camara L.), quando verdes, as folhas e os frutos são tóxicos e, se ingeridos pelos animais, causam danos diretos ao fígado, causando lesões graves. 
A dormideira (Mimosa pudica) merece destaque, pois apresenta espinhos em seus ramos que podem impedir o pastejo nas suas proximidades ou mesmo ferir os animais (SANTOS et al., 2004). Segundo Barbosa et al. (2009), animais sobre pastagens com infestação de dormideira apresentaram grande número de lesões, sendo recomendado o controle na área do presente trabalho para o melhor pastejo dos animais.

Diante dos resultados, ressalta-se a importância do levantamento da composição florística em pastagens, pois é uma valiosa ferramenta de suporte às recomendações de manejo. Assim, o manejo adequado evita níveis extremos de degradação, como também, possíveis danos aos animais.

\section{CONCLUSÕES}

As árvores foram representativas na área de estudo e destaca-se a importância de conservá-las nas pastagens, pois além de fornecer sombra ao gado bovino, prestam serviços ambientais essenciais para manter a conservação do ecossistema no qual estão inseridas, como o controle da erosão, manutenção da fertilidade do solo e retenção de água, contribuindo significativamente para evitar a degradação das pastagens, assim como o fortalecimento do potencial de regeneração florestal da região.

\section{REFERÊNCIAS}

AGAREZ,F.V.;RIZZINI,C.M.;PEREIRA,C.; Botânica: taxonomia, morfologia e reprodução das Angiospermae. Rio de Janeiro: Âmbito cultural, 1994. 256 p.

APG [ANGIOSPERM PHYLOGENY GROUP] IV An update of the Angiosperm Phylogeny Group classification for the orders and families of flowering plants. Botanical Journal of the Linnean Society, London, 181, n. 1, 2016.

BHAGWAT,S.A.; WILLIS,K.J.; BIRKS, H.J.B.; WHITTAKER, R.J.; Agroforestry: a refuge for tropical biodiversity? Trends in Ecology \& Evolution, v. 23, p. 261-267, 2008.

BRIGHENTI, A.M.; OLIVEIRA,M.F.; Biologia de Plantas Daninhas. IN: OLIVEIRA JUNIOR, R. S.; CONSTANTIN, J.; INOUE, M. H. (Eds.). Biologia e Manejo de Planta Daninhas. Curitiba, PR: Omnipax, 2011. p.1-36.

CASTRO, C. R. T; PACIULLO D. S. C. Boas práticas para a implantação de sistemas silvipastoris. Juiz de Fora: Embrapa Gado de Leite. 2006. (Comunicado Técnico, 50).

CASTRO, W. A. Avaliação da Aptidão Agrícola das Terras do Projeto de Assentamento Assurini, localizado no município de Altamira - Pará. Anais do XVIII Simpósio Brasileiro de Sensoriamento Remoto - SBSR. 2017. INPE Santos - São Paulo. ISBN 978-85-17-00088-1.

DIAS-FILHO, M.B.; Diagnóstico das Pastagens no Brasil. Empresa Brasileira de Pesquisa Agropecuária. Embrapa Amazônia Oriental. Documentos 402., 2014. 36 p. 
Disponível

em:

<https://www.infoteca.cnptia.embrapa.br/bitstream/doc/986147/1/DOC402.pdf>; Acesso em: 11 ago. 2020.

DIAS-FILHO,M.B.; Degradação de pastagens: processos, causas e estratégias de recuperação. 4 ed.rev. atual. e ampl. ed., Embrapa Amazônia Oriental. Belém-PA. 2011. 215p.

DUBREUILI, V.; FANTE, K.P.; PLANCHON,O.; SANT'ANNA NETO,J.L.; Climate change evidence in Brazil from Köppen's climate anual types frequency. International Journal of Climatology. 2019, 39, 1446-1456. https://doi.org/10.1002/joc.5893.

EMBRAPA - Empresa Brasileira de Pesquisa Agropecuária. Qualidade da carne do campo à mesa. Ministério da Agricultura, Pecuária e Abastecimento. 2018. Disponível em: <https://www.embrapa.br/qualidade-da-carne/carne-bovina/producaode-carne bovina/pastagem>. Acesso em: 11 ago. 2020

FERREIRA, E. A.; FERNANDEZ, A.G.; SOUZA, C.P.; FELIPE, M.A.; SANTOS, J.B.; SILVA, D.V.; GUIMARÃES, F.A.R.; Levantamento fitossociológico de plantas daninhas em pastagens degradadas do Médio Vale do Rio Doce, Minas Gerais. Revista Ceres, 61(4), 502-510. 2014.

IBGE - Instituto Brasileiro de Geografia e Estatística. Censo Agropecuário. 2010. Disponível em: <http://www.ibge.gov.br/home/estatistica/>; Acesso em: 15 de ago. 2018.

LIMA, A.K. O.; ARAÚJO, M.S. B.; SANTOS, N.F.A.; MELO, M.R.S.; SOUSA, V.Q.; PEDROSO, A.J.S.; BORGES, L.S.; FREITAS, L.S.; Composição florística e fitossociologia de plantas espontâneas em pastagens do gênero Brachiaria (syn. Urochloa) no nordeste paraense. Agroecossistemas, v. 9, n. 2, p. $339-349,2017$, ISSN online 2318-0188.

LORENZI,H.; NICOLAI, M.; BIANCHI, M. A.; INOUE M.H., CORREIA N. M.; CHRISTOFFOLETI, P. J.; VIDAL, R.; VICTORIA FILHO R.; OLIVEIRA JUNIOR R.S; GUIMARÃES, S. C. Manual de identificação e controle de ervas daninhas. $7^{0}$ edição. São Paulo: Instituto Plantarum. 2014.. 384 p.

LORENZI, H.; LACERDA, L.B.; BACHER, L.B.; Frutas do Brasil: nativas e exóticas. São Paulo: Instituto Plantarum. 2015. 768 p.

MENEZES, D.S.; GALVAO, A.K.L.; SILVA, J.F.; CAVALCANTE, D.P.; MONTEIRO, G.F.P.; Levantamento fitossociológico em pastagem no município de manaus, AM. XXVII Congresso Brasileiro da Ciência das Plantas Daninhas. Ribeirão Preto - SP. 2010. Disponível em: <https://www.researchgate.net/publication/268062873/download>. Acesso em: 11 ago. 2020 
MOTA, V.A.; Integração lavoura - pecuária - floresta na recuperação de pastagens degradadas no Norte de Minas Gerais. 2009. 112 p. Dissertação (Mestrado em Ciências Agrárias) - Universidade Federal de Minas Gerais, Montes Claros, 2010.

PELISSARI, A.; MENDONÇA, C.G.; LANG, C.R.; BALBINOT JR, A.A.; Avanços no controle de plantas daninhas no sistema de integração lavoura-pecuária. Synergismus Scyentifica, v.6, n.2, p.1-17, 2011.

RODRIGUES, I.M.C.; SOUZA FILHO, A.P.S.; FERREIRA, F.A.; DEMUNER, A.J. Prospecção química de compostos produzidos por Senna alata com atividade alelopática. Planta Daninha, v. 28, p. 1-12, 2010.

SANTOS, L.D.T.; SANTOS, I.C.; OLIVEIRA, C.H.; SANTOS, M.V.; FERREIRA, F.A.; QUEIROZ, D.S.; Levantamento fitossociológico em pastagens degradadas sob condições de várzea. Planta Daninha, Viçosa-MG, v. 22, n. 3, p. 343-349, 2004.

SILVA, C.S.; AUGUSTO, S.G.; ANDRADE, A.U. ;Agrometeorological characterization of Altamira, PA. In. IX Semana de Integração das Ciências Agrárias, UFPA, Altamira, PA: Anais. 2009, p. 148-154.

SOUZA, L.S.; VELINI, E.D.; MAIOMONIRODELLA, R.C.S.; Efeito alelopático de plantas daninhas e concentrações de capimbraquiária (Brachiaria decumbens) no desenvolvimento inicial de eucalipto (Eucalyptus grandis). Planta Daninha, v. 21, n. 3, p. 343-354, 2003.

TUFFI SANTOS, L.D.; SANTOS, I.C.; OLIVEIRA, C.H.; SANTOS, M.V.; FERREIRA, F. A.; QUEIROZ, D.S.; Levantamento fitossociológico em pastagens degradadas sob condições de várzea. Planta daninha. Viçosa, v. 22. n. 3, jul./set. 2004. 